\title{
Ischaemic colitis and immune complexes during gold therapy for rheumatoid arthritis
}

\author{
A. WRIGHT, * G. F. A. BENFIELD, AND D. FELIX-D A VIES \\ From the Department of Rheumatology, East Birmingham Hospital, Bordesley Green East, \\ Birmingham B9 5ST
}

SUMMARY A 35-year-old female with rheumatoid arthritis developed an ischaemic colitis and circulating immune complexes following her fourth injection of sodium aurothiomalate. The immune-complex titres fell rapidly after resolution of the colitis, and a possible association of these immune complexes and the bowel pathology is suggested.

Of the gastrointestinal side effects attributed to parenteral gold therapy those affecting the large bowel are uncommon. Enterocolitis is a rare associated disorder which is usually severe and widespread, and carries a high mortality. ${ }^{1}$ We report the first case of acute segmental ischaemic colitis following the introduction of gold therapy and associated with circulating immune complexes.

\section{Case report}

A 35-year-old Caucasian female with a 5-year history of seropositive rheumatoid arthritis involving her hands, wrists, and elbows was, after a test dose of 20 $\mathrm{mg}$, started on a weekly $50 \mathrm{mg}$ injection of sodium aurothiomalate (Myocrisin) because of further clinical and radiological deterioration of her affected joints. Throughout her illness there had been no systemic vasculitis or other extra-articular manifestations, and there was no history of any gastrointestinal disorder. Her medication included ketoprofen and ferrous sulphate but not oral contraceptives.

Two days after her fourth gold injection she was admitted with a 4-hour history of colicky, lower abdominal pain associated with frequent bloody diarrhoea. There was tenderness and guarding in the hypogastrium, bowel sounds were reduced, and

Accepted for publication 26 July 1983.

* Present address: St Mary's Hospital, Portsmouth.

Correspondence to Dr D. Felix-Davies. rectal examination revealed water and greenishblack stools only. Apart from her joint changes there was no evidence of active rheumatoid disease, and cardiovascular examination showed no abnormality.

Investigations revealed a haemoglobin of 13.4 $\mathrm{g} / \mathrm{dl}$, white cell count of $14.9 \times 10^{\%} / 1$ (95\% neutrophils), and an ESR of $18 \mathrm{~mm} / \mathrm{h}$. Orosomucoid was raised at $1.6 \mathrm{~g} / \mathrm{l}$ (normal range $0 \cdot 6-1 \cdot 2 \mathrm{~g} / \mathrm{l})$. Blood and stool examination for pathogens was normal, but a barium enema (Fig. 1) gave a classical picture of ischaemic colitis with scalloping ('thumb-printing'), thickened mucosal folds, and spasm and rigidity of the distal transverse and proximal descending colon. A few discrete ulcers throughout the affected segment were seen. Colonoscopy revealed patchy erythema with punctate haemorrhage and microulceration from $20 \mathrm{~cm}$ extending proximally. Biopsies showed normal areas and sharply demarcated ulcerated areas with adjacent regenerative glands. In these ulcerated areas there was overlying fibrin, a single layer of regenerative surface epithelium, and underlying increased vascularity, fibrosis, and nonspecific inflammation. Vasculitis and granulomata were absent, the features being strongly suggestive of an ischaemic colitis.

The patient was treated conservatively with intravenous and oral fluids, and became asymptomatic 10 days after admission. Further investigations during this period showed normal immunoglobulins and complement levels and a Rose-Waaler titre of 1:32. Mesenteric and coeliac angiography revealed patent normal vessels throughout. However, immune com- 


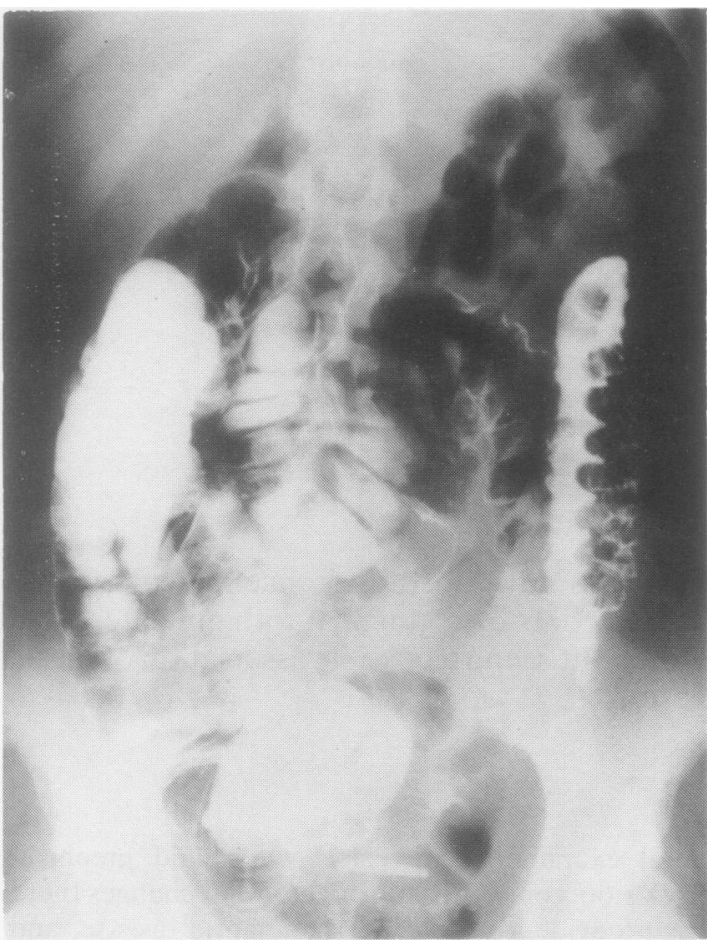

Fig. 1 Appearance of distal large bowel during barium enema examination. Marked 'thumb printing' and spasms are evident.

plex titres of 1:160 (platelet aggregation) were obtained during the acute phase, which fell and became negative over a 50-day period (Fig. 2). A second colonoscopy and biopsy 13 days after the first was normal, and a subsequent small-bowel followthrough $x$-ray examination showed no abnormality.

\section{Discussion}

Gold-associated enterocolitis ${ }^{2}$ and ischaemia or infarction of the bowel associated with rheumatoid vasculitis $^{3}$ are 2 disorders which occur rarely. Both carry a high mortality, and even in the survivors the illness is severe. In this instance, however, a patient presented with an apparently localised ischaemic colitis early in the course of gold therapy. The illness was of short duration and associated with raised levels of circulating immune complexes, which disappeared as she recovered. Reports describing mesenteric rheumatoid vasculitis ${ }^{34}$ note that it is associated with severe generalised rheumatoid disease, cutaneous vasculitis, subcutaneous nodules, active arthritis, reduced complement levels, and high titres of rhe umatoid factor. These features were not shown by our patient, so that it is unlikely that this was the pathogenesis in this instance. The patient also had no evidence clinically, radiologically, or histologically to support a diagnosis of a thromboembolic disorder or of ulcerative colitis or Crohn's disease.

However, the presence in the acute stage of circulating immune complexes, not previously reported in rheumatoid patients with bowel disease, may have induced a localised vasculitis at a site which is known to contain relatively poor anastomoses. Support for a localised immune-complex-mediated ischaemia lies in the disappearance of these complexes as the condition resolved, together with the absence in a relatively young patient of any cardiovascular or previous gastrointestinal disorder. The acute presentation followed a small dose of gold $(170 \mathrm{mg})$, implying an immune-mediated hypersensitivity reaction-a pathogenesis suggested by a previous report of invitro lymphocyte transformation in a patient with gold-associated enterocolitis. ${ }^{5}$

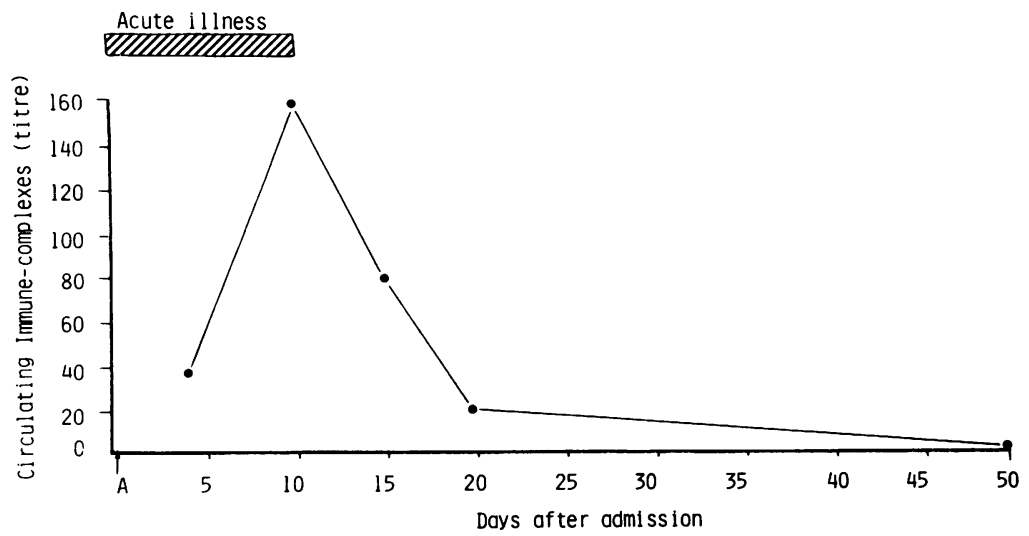

Fig. 2 Circulating immune complexes during and following the episode of ischaemic colitis. 


\section{References}

1 Stein H B, Urowitz M B. Gold induced enterocolitis: case report and literature review.J Rheumatol 1976; 3: 21-6.

2 Fam A G, Paton T W, Shames C J, Lewis A J. Fulminant colitis complicating gold therapy. J Rheumatol 1980; 7: 479-85.
3 Adler R H, Norcross B M, Lockie L M. Arteritis and infarction of the intestine in rhe umatoid arthritis. JAMA 1962; 180: 922-6.

4 Scott D G I, Bacon P A, Tribe C R. Systemic rheumatoid vasculitis: a clinical and laboratory study. Medicine 1981; 60: 288-97.

5 Szpak M W, Johnson R C, Brady C E. Gold induced enterocolitis. Gastroenterology 1979; 76: 1257. 